\title{
Evaluation of an Expedient Terrorist Vehicle Barrier
}

\author{
D. McCallen, B. Wattenburg, P. Lewis, P. Mote
}

February 28, 2000 


\section{DISCLAIMER}

This document was prepared as an account of work sponsored by an agency of the United States Government. Neither the United States Government nor the University of California nor any of their employees, makes any warranty, express or implied, or assumes any legal liability or responsibility for the accuracy, completeness, or usefulness of any information, apparatus, product, or process disclosed, or represents that its use would not infringe privately owned rights. Reference herein to any specific commercial product, process, or service by trade name, trademark, manufacturer, or otherwise, does not necessarily constitute or imply its endorsement, recommendation, or favoring by the United States Government or the University of California. The views and opinions of authors expressed herein do not necessarily state or reflect those of the United States Government or the University of California, and shall not be used for advertising or product endorsement purposes.

This work was performed under the auspices of the U.S. Department of Energy by the University of California, Lawrence Livermore National Laboratory under Contract No. W-7405-Eng-48.

This report has been reproduced directly from the best available copy.

Available electronically at http://www.doe.gov/bridge

Available for a processing fee to U.S. Department of Energy and its contractors in paper from

U.S. Department of Energy

Office of Scientific and Technical Information

P.O. Box 62

Oak Ridge, TN 37831-0062

Telephone: (865) 576-8401

Facsimile: (865) 576-5728

E-mail: reports@adonis.osti.gov

Available for the sale to the public from

U.S. Department of Commerce

National Technical Information Service 5285 Port Royal Road Springfield, VA 22161

Telephone: (800) 553-6847

Facsimile: (703) 605-6900

E-mail: orders@ntis.fedworld.gov

Online ordering: http://www.ntis.gov/ordering.htm

OR

Lawrence Livermore National Laboratory

Technical Information Department's Digital Library

http://www.llnl.gov/tid/Library.html 


\section{Evaluation of an Expedient Terrorist Vehicle Barrier}

A Laboratory Directed Research and Development (LDRD) feasibility study

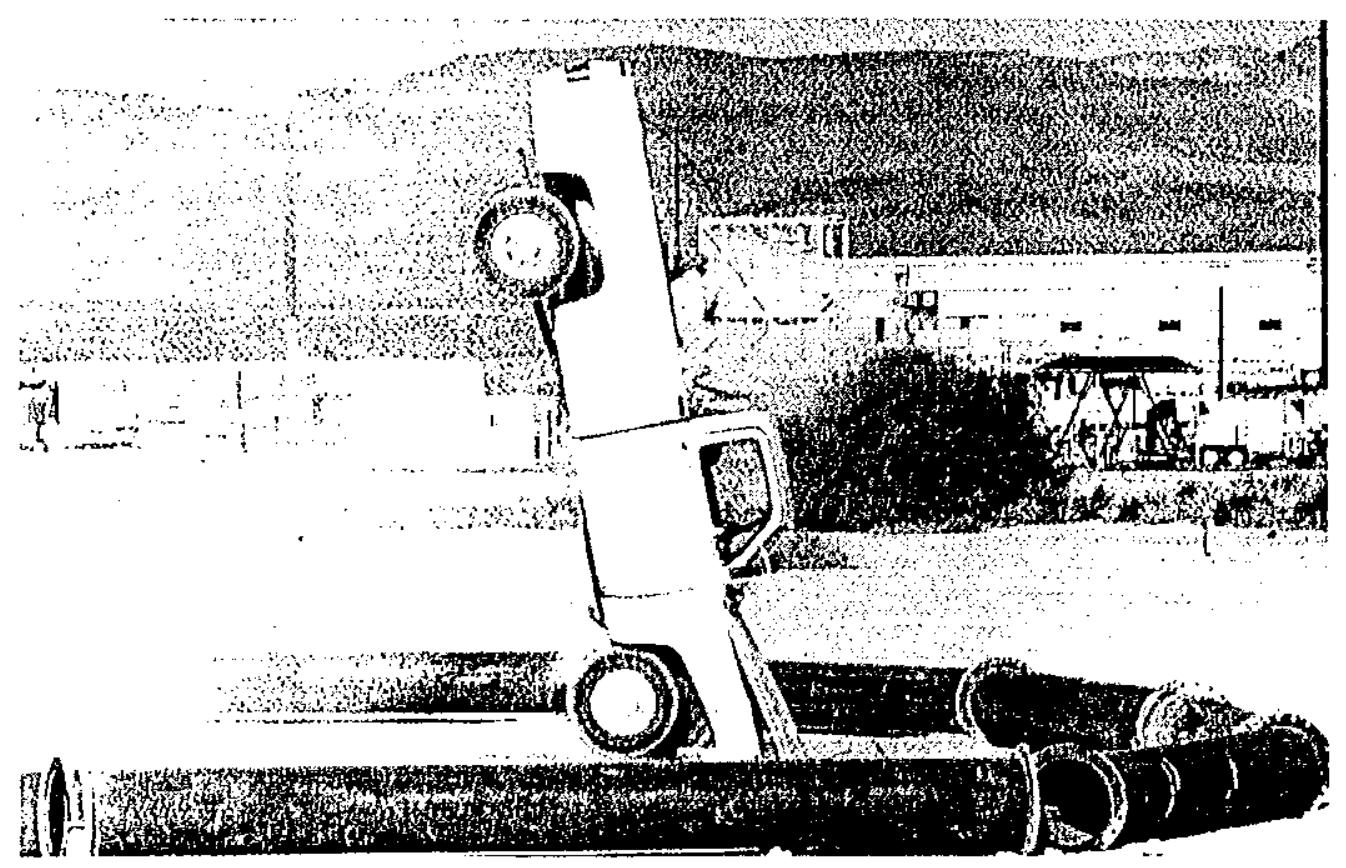

Divid McCillen

Center for Complex Distributed Systems

Lawrence Livermore National Laboratory

Pattrick Lewis

Defense Sciences Engineering Division

Lalwrence Livermore National Laboratory
Bill Wattenburg

University Foundation

California State University. Chico

Pete Mote

Nevada Testing Institute

Las Vegas, Nevada 


\title{
Evaluation of an Expedient Terrorist Vehicle Barrier
}

A Laboratory Directed Research and Development (LDRD) feasibility study

\author{
David McCallen \\ Center for Complex Distributed Systems \\ Lawrence Livermore National Laboratory \\ Bill Wattenburg \\ University Foundation \\ California State University, Chico \\ Patrick Lewis \\ Defense Sciences Engineering Division \\ Lawrence Livermore National Laboratory \\ Pete Mote \\ Nevada Testing Institute \\ Las Vegas, Nevada
}

\begin{abstract}
The threat of terrorist vehicle bombs has become evident in the past few years. The explosive power that can be generated by a "home made" bomb carried by a standard van or moderate size truck can generate sufficient blast overpressures to cause major damage or catastrophic collapse to building structures. There are a number of means available to help prevent a successful terrorist attack on a facility. One measured consists of the gathering of intelligence that can be used to thwart an attlack before it takes place. The design and retrofit of structures and structural systems which can resist blast loadings and protect occupants is another area which is currently receiving a great deal of attention by the security community. Another measure, which can be used to protect many existing facilities, is to restrict access to the facility. This option consists of keeping unauthorized vehicles as far as possible from the facility so that if a velicle bomb does approach the facility, the distance at which the bomb is detonated will result in significant reduction in the overpressures by the time the blast wave reaches the protected structure. This paper describes a simple and efficient vehicle barrier concept that can be used to prevent unauthorized vehicle access. The feasibility study described herein consisted of a field experimental program to test the validity of the barrier concept, and demonstrated the ability of the simple barricr to effectively disable speeding vehicles.
\end{abstract}

Evatuation of an Expedient Terronst Vihncle Banter: 


\subsection{Background}

Recent events in the U.S. and abroad have demonstrated the potential for terrorist vehicle bombs to cause massive destruction to important facilities (Table 1). The effects of a vehi-

TABLE 1. Terrorist attacks against U.S. assets, 1983-1998.

\begin{tabular}{cc}
\hline Terrorist Event & Casualties \\
\hline 1983 Car Bomb. U.S. Embassy, Lebanon & 63 killed \\
1984 Car Bomb. U.S. Embassy, Lebanon & 11 killed \\
1986 Bomb, La Belle Disco, Germany & 2 killed \\
1993 Car Bomb. World Trade Center, USA & 6 killed, 1000 injured \\
1995 Car Bomb. U.S. Barracks, Saudi Arabia & 7 injured \\
1995 Car Bumb. Federal Building, USA & 168 killed \\
1996 Carr Bumb. U.S. Barracks, Saudi Arabia & 19 killed \\
1998 Car Bomb. U.S. Limbalssy, Tanzania & 11 killed \\
1948 Car Bumb. U.S. Embassy, Kenya & 213 killed. 5400 injured \\
\hline
\end{tabular}

cle bomb on at major structure can range from destruction of the cladding (i.e. the nonstructural wall elements) of the structure, to progressive collapse of the structure. Progressive collapse occurs when a bomb blast causes sufficient local damage to the structure that the vertical gravity load path of the structure is destroyed and the gravity loads on the structure then lead to overall collapse of the structure (Figure 1). The structural system type can play a large role in decrmining whether or not progressive collapse occurs. The attack at the Murah Building in Oklahoma City for example resulted in progressive collapse of a large portion of the building structure (Figure 2). The Murray Building was a reinforced concrete frame structure and the vehicle bomb caused extensive local destruction of the columns and the vertical gravity load path was destroyed locally. The existing lrame system was incapable of redistributing the gravity load, and vertical collapse of the frame structure ensued. A similar attack occurred on the Khobar Tower building in Saudi Arabia (Figure 2). However, this structural system consisted of a shear wall lateral load system as opposed to the frame system of the Murrah Building. The result was that the powerful bomb caused extensive failure of external cladding, but the vertical load system was not scverely damaged and the structure did not suffer progressive collapse.

The extensive damage caused by terrorist bombs is a result of the tremendously large overpressures which can be generated by a bomb created from readily obtainable commercial use materials. For example, the overpressures created at various distances for an explosive equivalent to $5000 \mathrm{lbs}$ of TNT are shown in Figure 3 . A terrorist can create this level of 


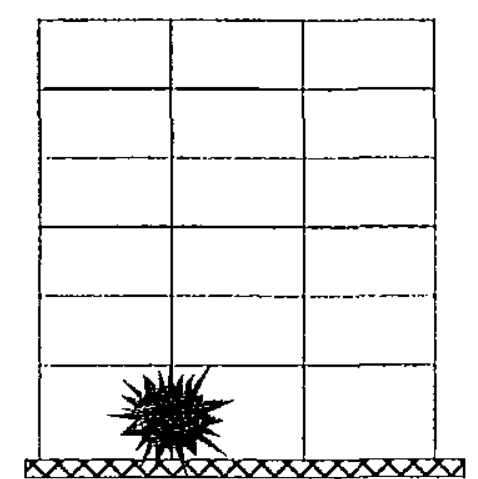

Bomb blast rapidly destroys columns

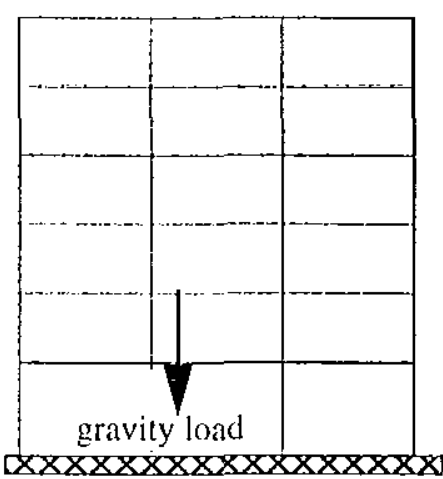

Gravity load-path is removed

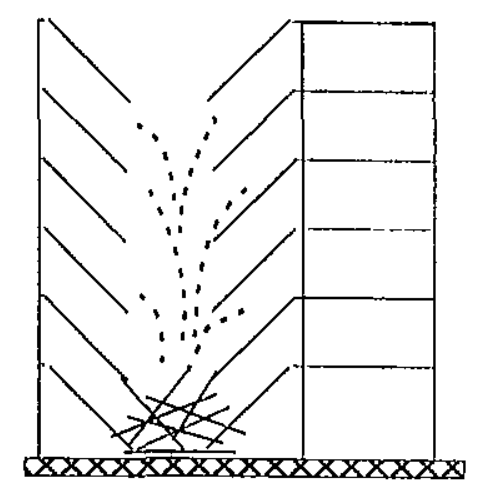

"Slow" progressive collapse occurs

FIGURE 1. Progressive collapse of a building.

a)

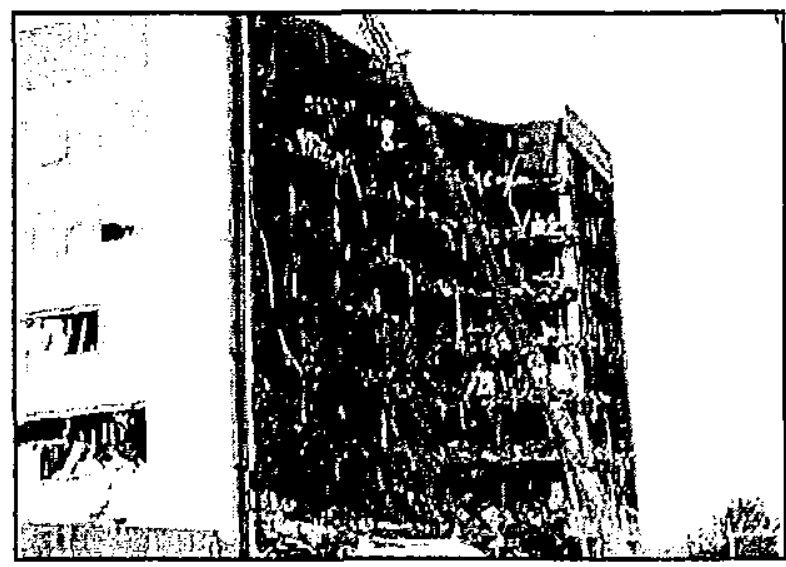

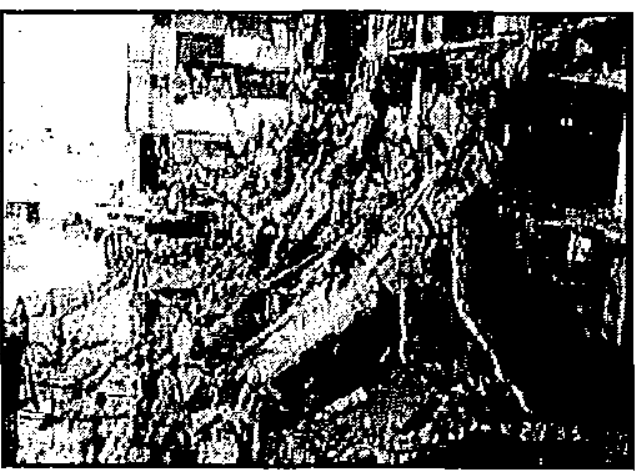

b)

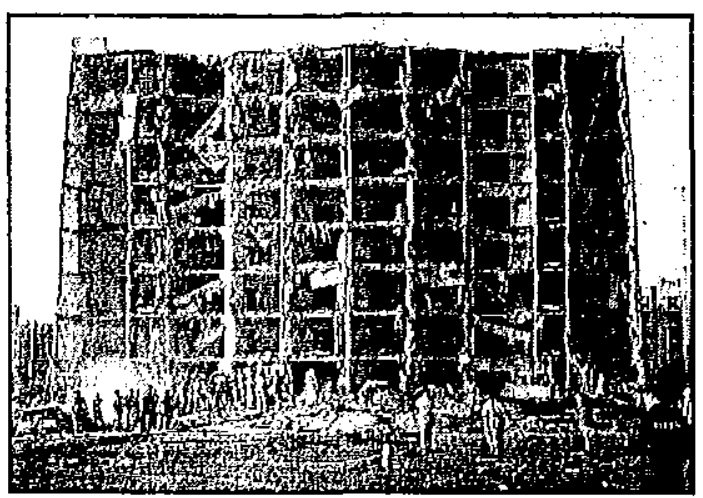

FIGURE 2. Terrorist attacks on U.S. infrastructure. a) Domestic terrorist attack on the Murrah Building, Oklahoma City resulting in progressive collapse; b) terrorist attack on the Khobar Tower Building, Saudi Arabia, resulting in extensive cladding destruction. 


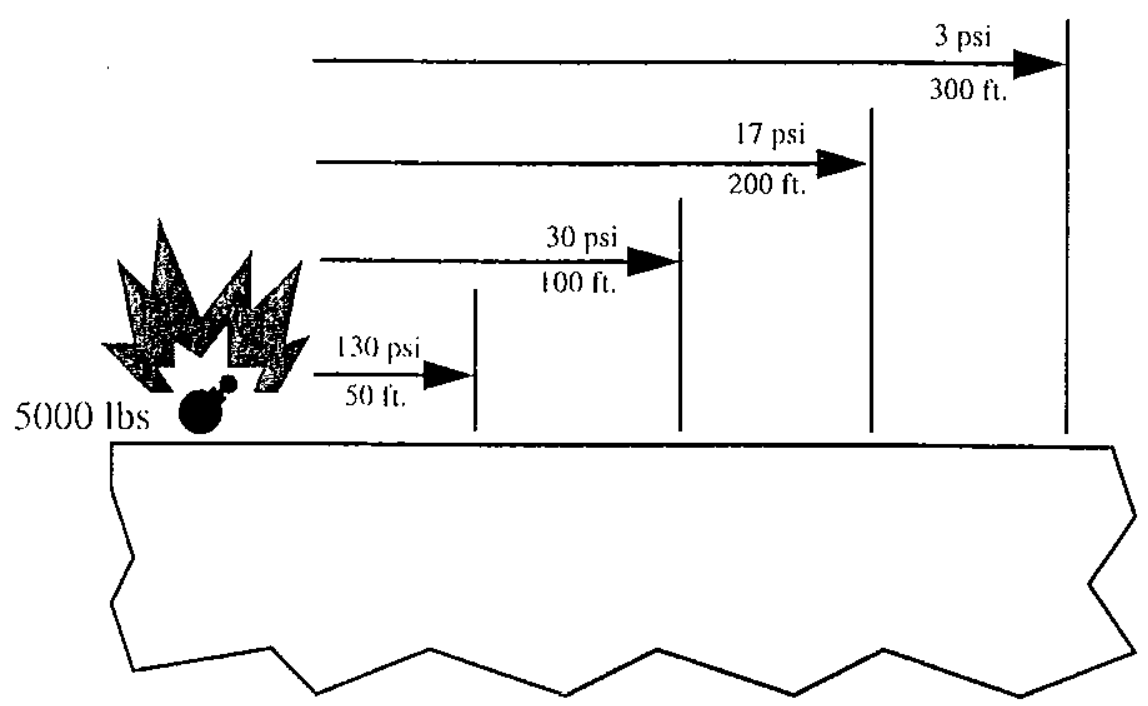

FIGURE 3. Blast overpressures as a function of distance for a bomb equivalent to $\mathbf{5 0 0 0}$ pounds of 'TNT.

explesive with ammonium nitrate and fuel oil (ANFO) materials. Typical building structures maly survie overpressures in the $2-3$ psi range, but will likely be destroyed by overpresstures on the order 10 10-15 psi. Thus Figure 3 indicates that a significant stand-olf distance must be maintained in order to protect a structure from a powerful vehicle bomb. This is obriously not featsible for many structures, such as important buildings located in downtown locations. However. for some important facilities, significant stand-off dislances are achievable. and even for tacilities where adequate stand-off cannot be achieved. maximizing the existing stand-olf can assist in protecting the occupants.

The possibilities for stopping unathorized vehicle access to critical facilities consist of human intervention, where armed guards are posted to prohibit passage, or physical barrier placement where a mechanical system is placed to prevent unauthorized vehicle passage. The human intervention alternative has proven a number of times to be an ineffectual method. Our notion of what represents rational behavior indicates that highly armed guards would provide a significant deterrent to a terrorist. However, a determined terrorist. willing to sacrifice their own life, is undeterred by bullets and bullets are ineffectual in slopping a speeding vehicle regardless of how many of the bullets strike the driver. In the altacks in Lebanon and Africa, armed guards were aware an attack was underway. but were unable to deter or prevent the attacks.

A number of possibilities exist lor creating a physical barrier. However, there are often conflicts between limiting access for unauthorized vehicles and allowing access to authorized vehicles. The most widely used method of denying access is through the use of concrete rail barriers such as those found along highways (the most familiar being the "New Jersey" barrier (lenoting the state where it was originally designed and constructed). These massive concrete barriers can be very effective in stopping vehicles, however, they are massive and heavy, which requires the use of heavy equipment for placement. Once 
placed, the barrier can only be moved by bringing in heavy lifting equipment, and cannot be quickly changed to allow access status for authorized vehicles. In addition, these barricrs may not be available in any location where a quick barrier is required, particularly at overscass sites where critical facilities or rapidly deployed forces might require short notice proteclion.

The purpose of the feasibility study described herein was to investigate the utility of a new alternate vehicle barrier concept. The alternative barrier, originally proposed by Wattenburg, consists of a steel cable strung through steel pipes and anchored on the ends as shown in Figure 4 . The barrier can be constructed from readily available materials, which

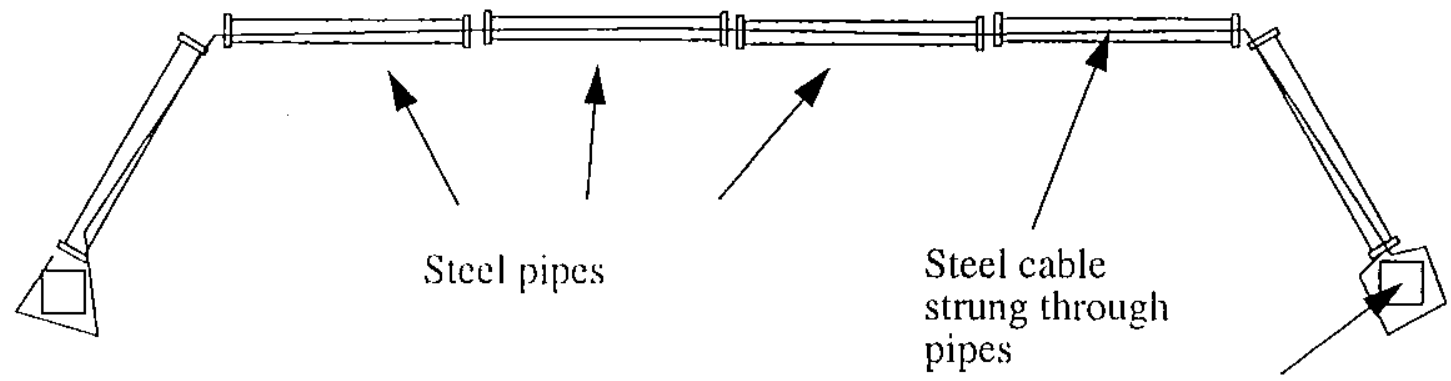

Barrier plan view

Mass anchors

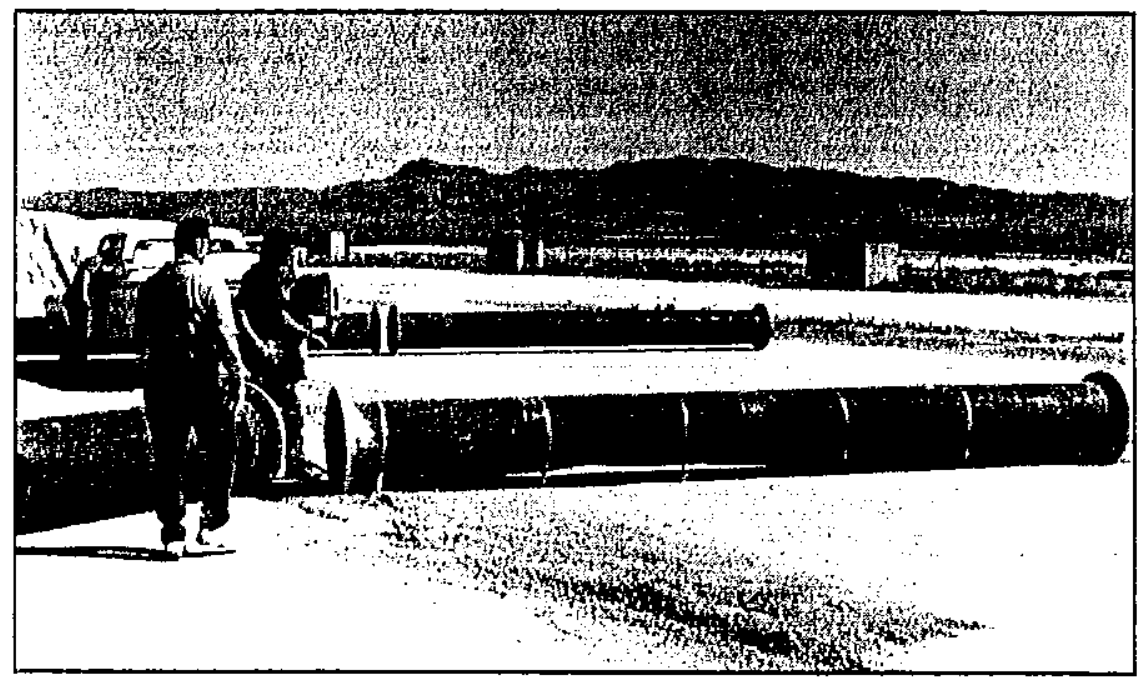

FIGURE 4. Flexible pipe barrier concept.

are obtainable essentially anywhere in the world, without the use of heavy equipment or specialized construction skills. The barrier is very light relative to concrete rail barriers and with the appropriate connection couplings, segments of the barrier could be moved by hand in a matter of minutes. The barrier is flexible provides some give when impacted by a speeding vehicle. The end masses provide the anchors for the cable system and react the inertial forces resulting from the vehicle impact. This barrier concept was tested with field 
experiments at the hazardous spill facility at the DOE's Nevada Test Site (NTS) north of Las Vegas.

\subsection{Evaluating the pipe barrier concept}

The pipe barrier concept was tested at the hazardous spill facility at NTS. The principal objective of this test was to ascertain the ability of the barrier to incapacitate a large speeding vehicle. Because of the remote location, and the availability of a flat wide open area, the NTS facility provided an ideal test bed for the barrier concept, and allowed for performance of a destructive test where the vehicles could be smashed into the barrier at high rates of speed.

The vehicle test area is shown in the photograph in Figure 5, this area provided an unrestricted vehicle run-up of approximately $600 \mathrm{ft}$. The site also had barrier construction

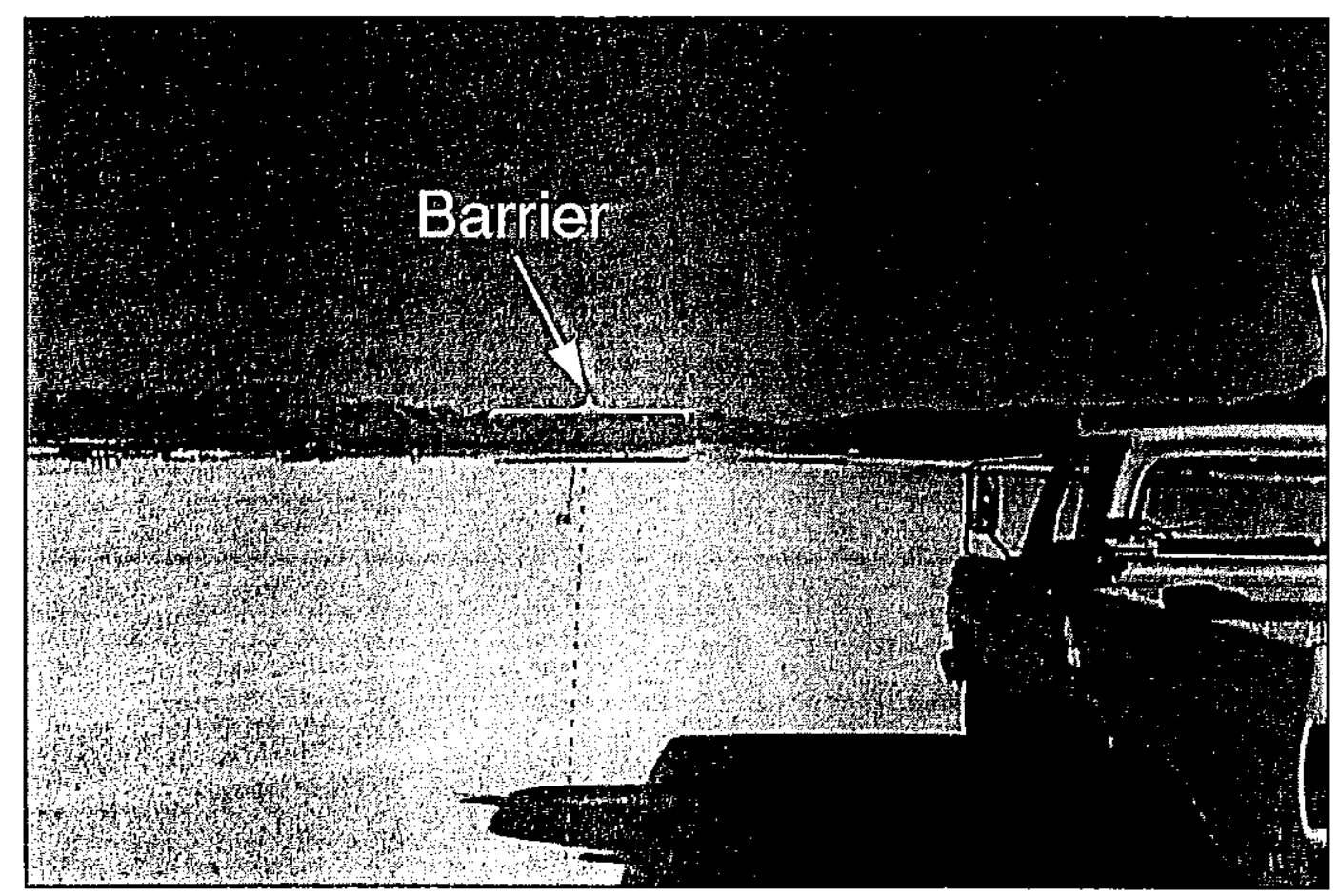

FIGURE 5. Vehicle run-up at the NTS spill facility.

materials available and two excess DOE vehicles were obtained from the NTS motorpool to serve as mock terrorist vehicles. The barrier was constructed with 24 inch steel pipe and one inch diameter steel cable. Existing concrete blocks were utilized as anchors at the ends of the barrier as shown in Figure 6. Since an objective of the experiment was to crash the vehicles into the barrier at high rates of speed, human drivers were out of the question and a remote control vehicle system was developed. The vehicle control system consisted of a radio commanded electronic control system mounted in the rear of the vehicle. The 


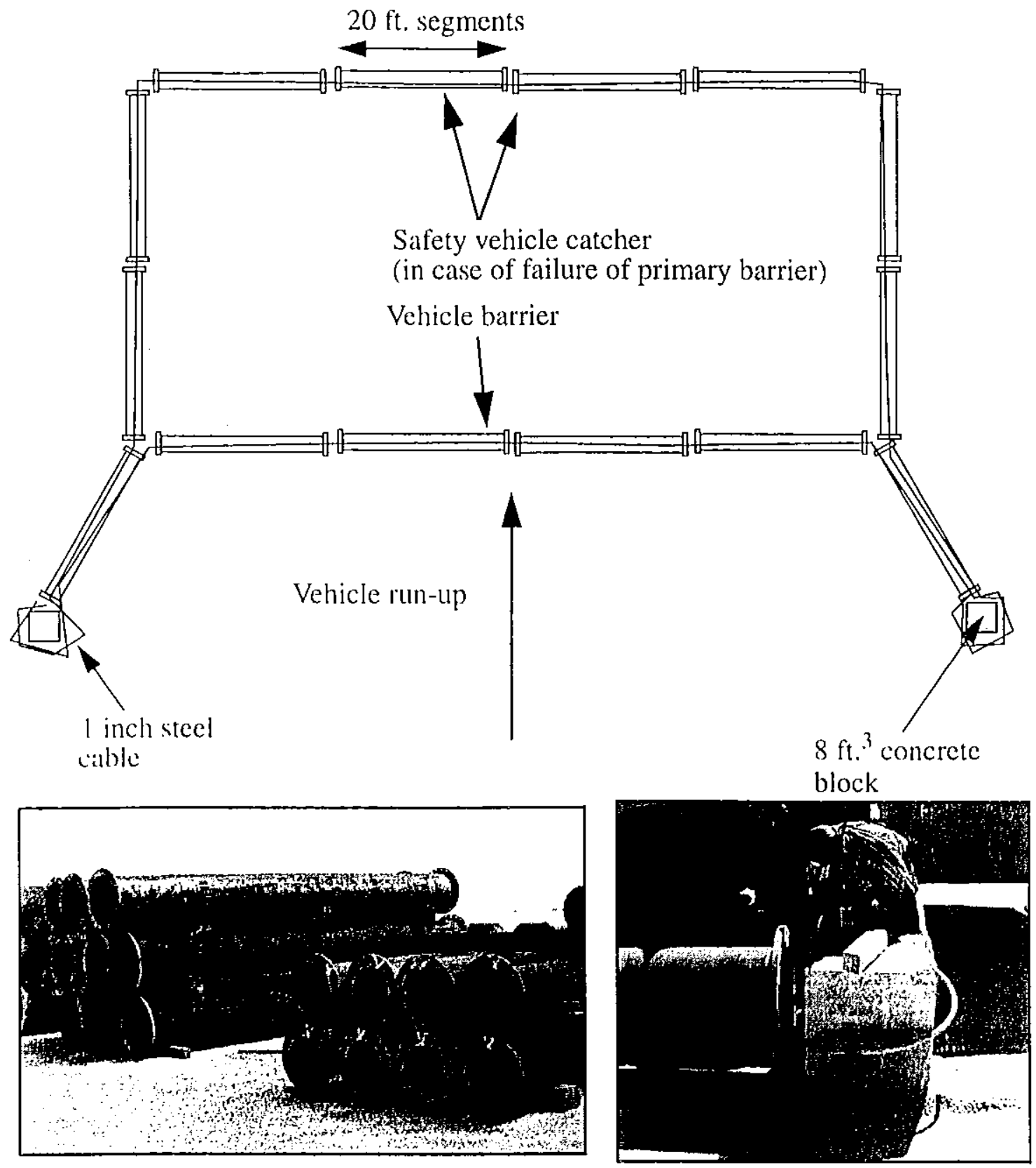

Existing 24 inch diameter steel pipe stock

FIGURE 6. Test set-up for the pipe barrier experiments.

control system sent commands to a system of servos and linkages in the truck cabs which controlled steering, gas pedal. and brake as shown in Figure 7. Safety was of paramount concern and special redundant safety features were included on the vehicle. The safety aspects included an ignition system kill from the radio control box, a "time-out" timer on the vehicle which would kill the ignition system after a specified number of seconds, an accelerometer triggered ignition kill feature which would kill the ignition system after the accelerometers sensed large accelerations associated with impact, and finally the original 
vehicles into the barriets at speeds which The field experiments consisted of running the vehicles into the bomb could practically achieve prior to were representative of what a terments were conducted. Tn the fir mock a bomb mass was impacting a batrier. Two experty 500 pounds of sames per hour. In this first experiment the truck loaded with approximat approximately 35 miles per andectively launched into the air. crashed into the barrier with tremendous impact and impact resulted in the mial impact also vehicle hit the bat vehicle indicated that the initia the vehicle radiator. The initian insion. The Inspection of the veunts and smashing up into just behind the vehicle than the original barfrom the motor mounte of the vehicle drive line just rupture imately $35 \mathrm{ft}$. beyond the cable would allow the resulted in ruplure came to rest right-side-up approx some slack in the cab the vehicle in the

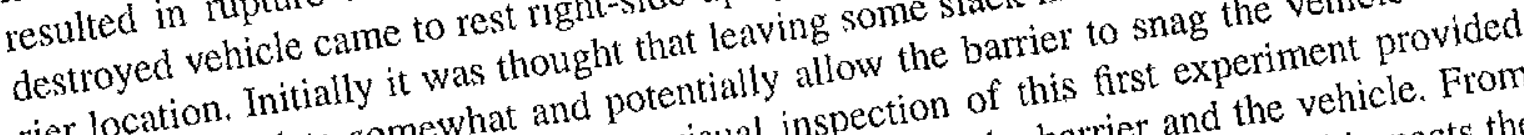
rier location. Instiate somewhat and potentialy inspection of this first ex the vehicle. From barriet to transtate Careful slow-motion visual ins between the ban at high speed impacts the barriet system. Care details of the interaction the vehicle moving at high sipes in the barrier some insight in motion animation, it was cleat that vertical direction befor the phich was purposefully the slow motion animally launched in a vertical the move. Thus the slack weforming barrier until have enough time to respond and begin the was not utilized by the derstertion, the cables were left in the barrier cable during this first barier. In light of this oberiment so that the impact would the vehicle was long gone over the second vehic The second vehicle test utilized ane ton truck maded with approximately 500 pounds of hour. Like the first experiment, this weight in the bed of the truck. With the tauge over the barrier, the sand to emulate some exp and the when the truck attempted to vertically in addition to the front of tem, the barrier was latenche the the the varrier as stiown taught cable system lat being the vehicle totally power train damage characteristics as sequence of the vehicle, the reshicle also exhibited the same per and broken drive shaft. 10.

first vehicle test, including a sheared off motor impact ar video segments illustrating

\subsection{Conclusions}

The expedient pipe bartier can be utilized to disable heavy duty, speeding terrotist vehicles. The experiments indicated that and tremendous forces and the drive train of the systempling jected to a violent impact and decoupling of the motor from the mente dynamic forces which result likely be disabled through. Everyone has experience the sump is hit at slightly too high a speed (santion of the drive line sy relatively small highway speed bump is "bump" and higher speed and

m.p.h.), extrapolate that to a much targe barier impact can be devel 

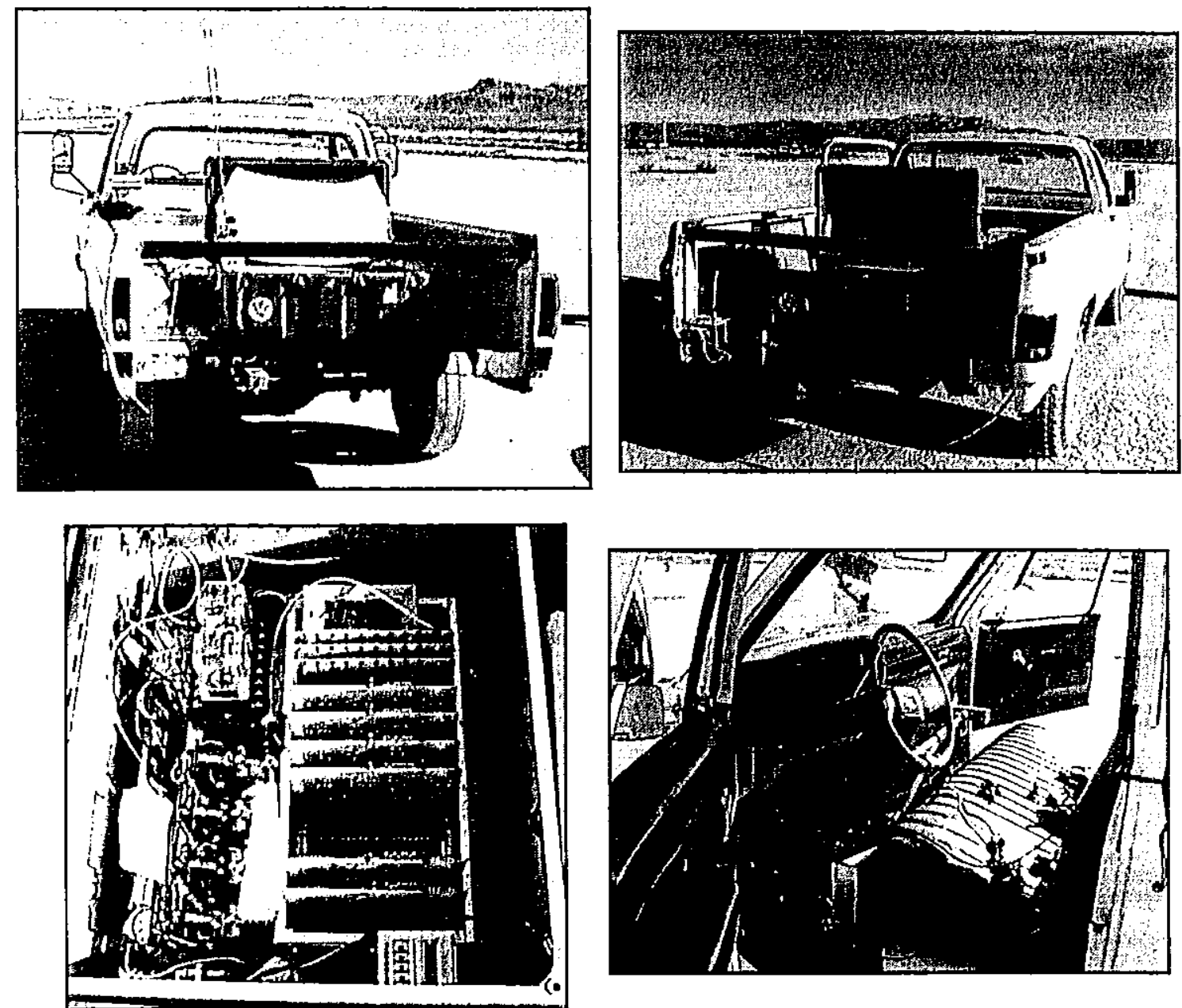

a)
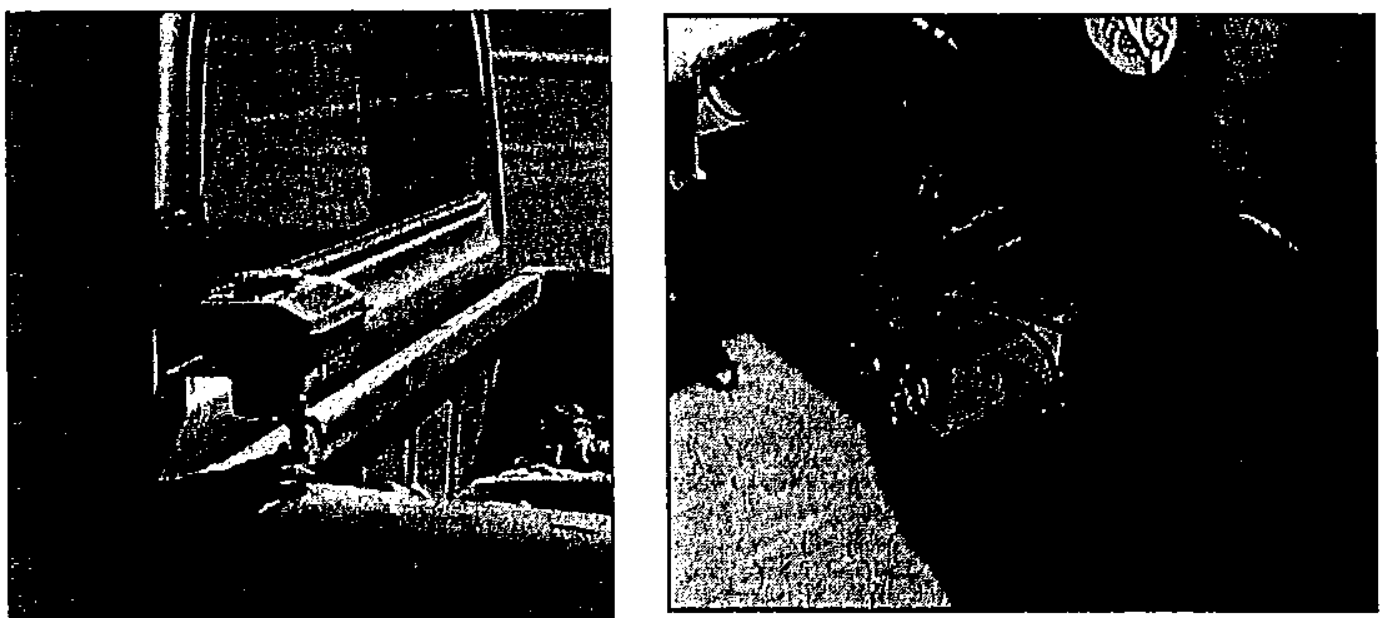

b)

FIGURE 7. Test vehicle hardware. a) Electronic controller and control servos and linkages; b) safety features including reduced gas reservoir and accelerometer for ignition kill. 


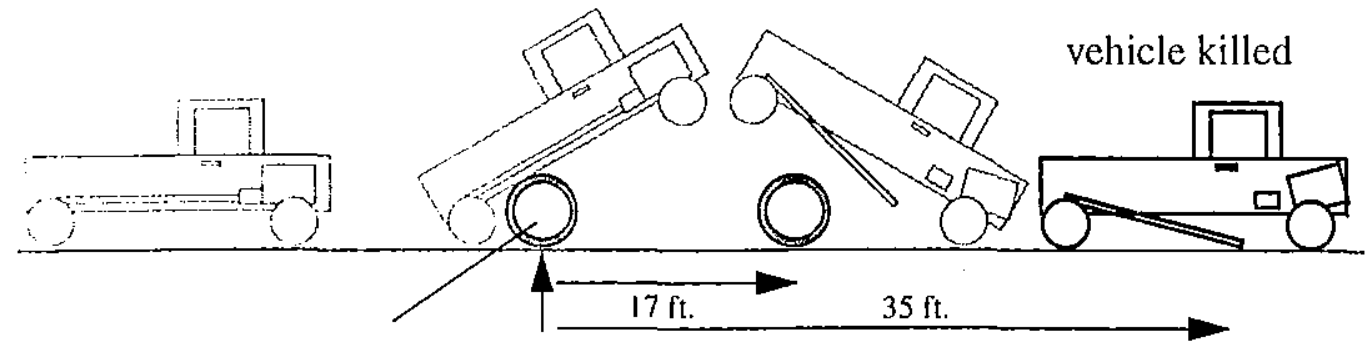

Initial impact

vehicle speed $=36 \mathrm{~m} . \mathrm{p} . \mathrm{h}$.
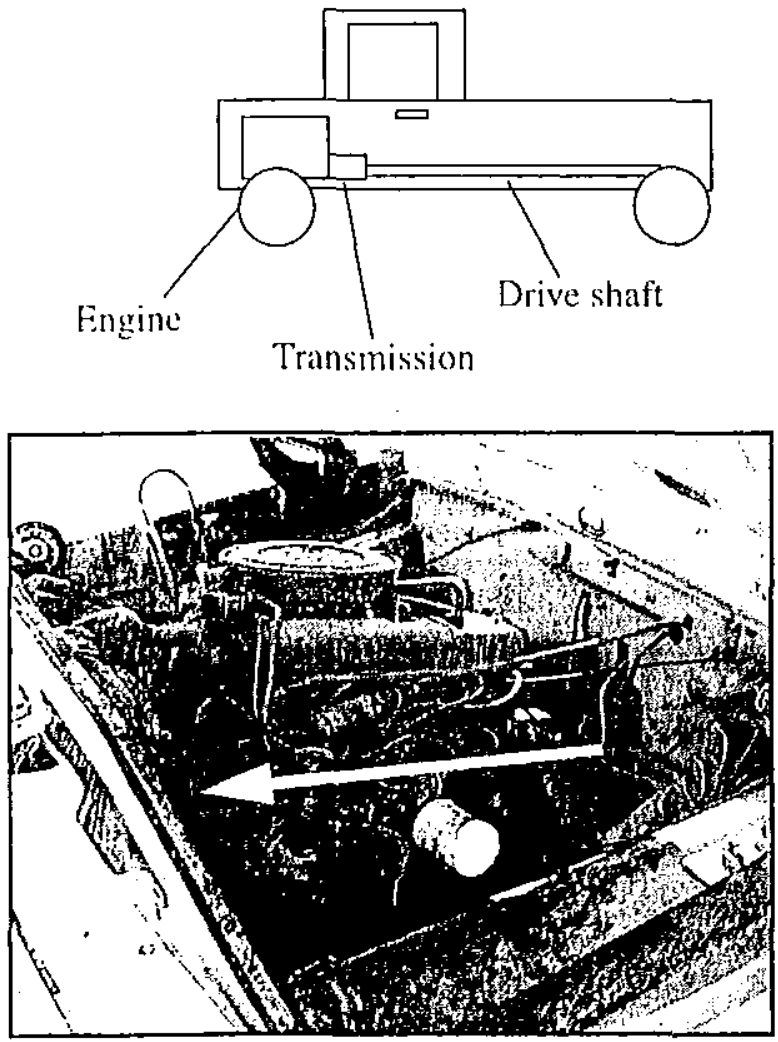

Engine sheared off and translated

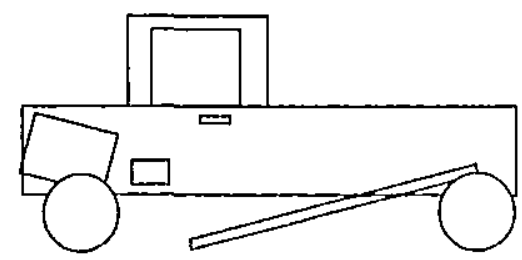

Power train destruction

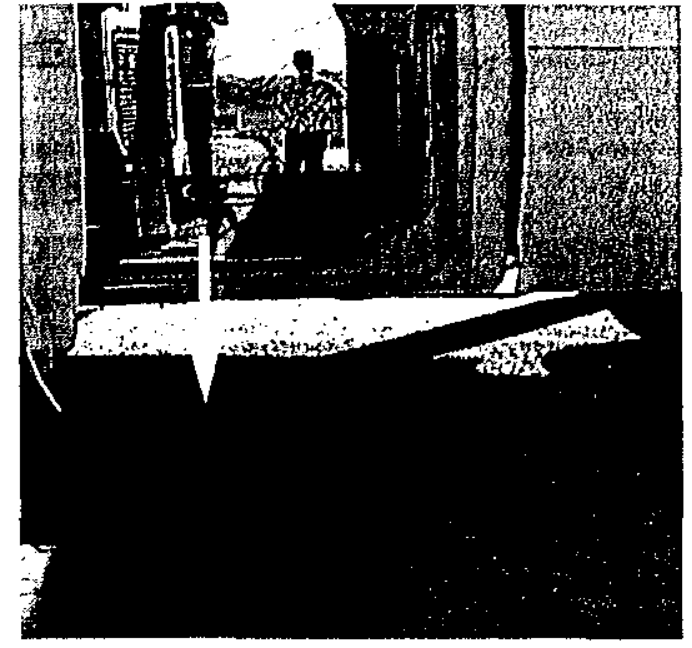

Drive shaft severed and dropped

FIGURE 8. Vehicle destruction from the first vehicle experiment.

The pipes used in the field experiment were 24 inches in diameter and this diameter was employed because of the availability from the existing pipe stockpile at NTS. With this diameter pipe, the bumpers of the trucks impacted near the top of the pipe. As a result, the vehicles tended to be launched vertically upon impact. So although the vehicles were completely disabled, they did physically end up over the barrier. It is likely that a larger diameter pipe, 36 inch pipe for example, would have less tendency for sending the vehicle in the vertical direction and would result in a more violent collision, with more energy trans- 

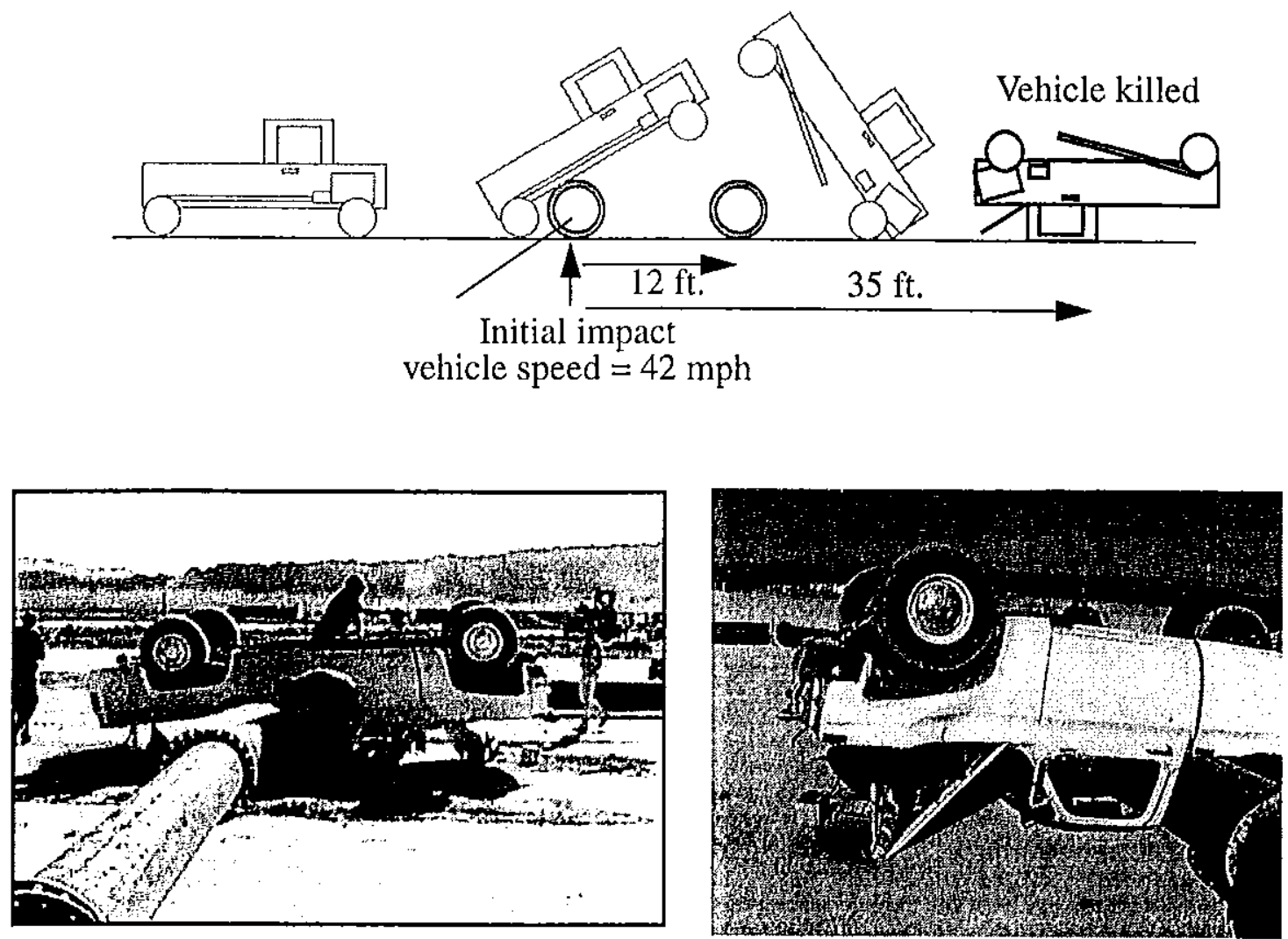

FIGURE 9. Vehicle destruction during the second field test.

ferred to the vehicle system, and would tend to snare the vehicle in the barrier rather than allow the vehicle to vault vertically and move over the barrier. In order to optimize the barrier design, it would be desirable to test larger diameter pipe barriers in the future to validate any fundamental improvements which might result in the barrier performance.

This expedient barrier should not necessarily be viewed as a replacement for standard concrete barriers for all applications. However, where a need arises for a quick and easily constructed barrier, which must be constructed from readily available materials on hand, this barrier design can be very useful to deny unauthorized vehicle access. The barrier also has potential for applications in which there is a mixed need for authorized vehicle access and unauthorized vehicle denial, where the barrier must be moved and replaced at frequent intervals.

\section{Acknowledgements}

This work was performed by the Lawrence Livermore National Laboratory under the auspices of the United States Department of Energy, contract number W-74054-Eng-48. This work is an account of a Laboratory Directed Research and Development feasibility study. The Nevada Testing Institute of Las Vegas assisted in arranging the field logistics for the test program and Bechtel Nevada provided field technicians for barrier construction and removal. 

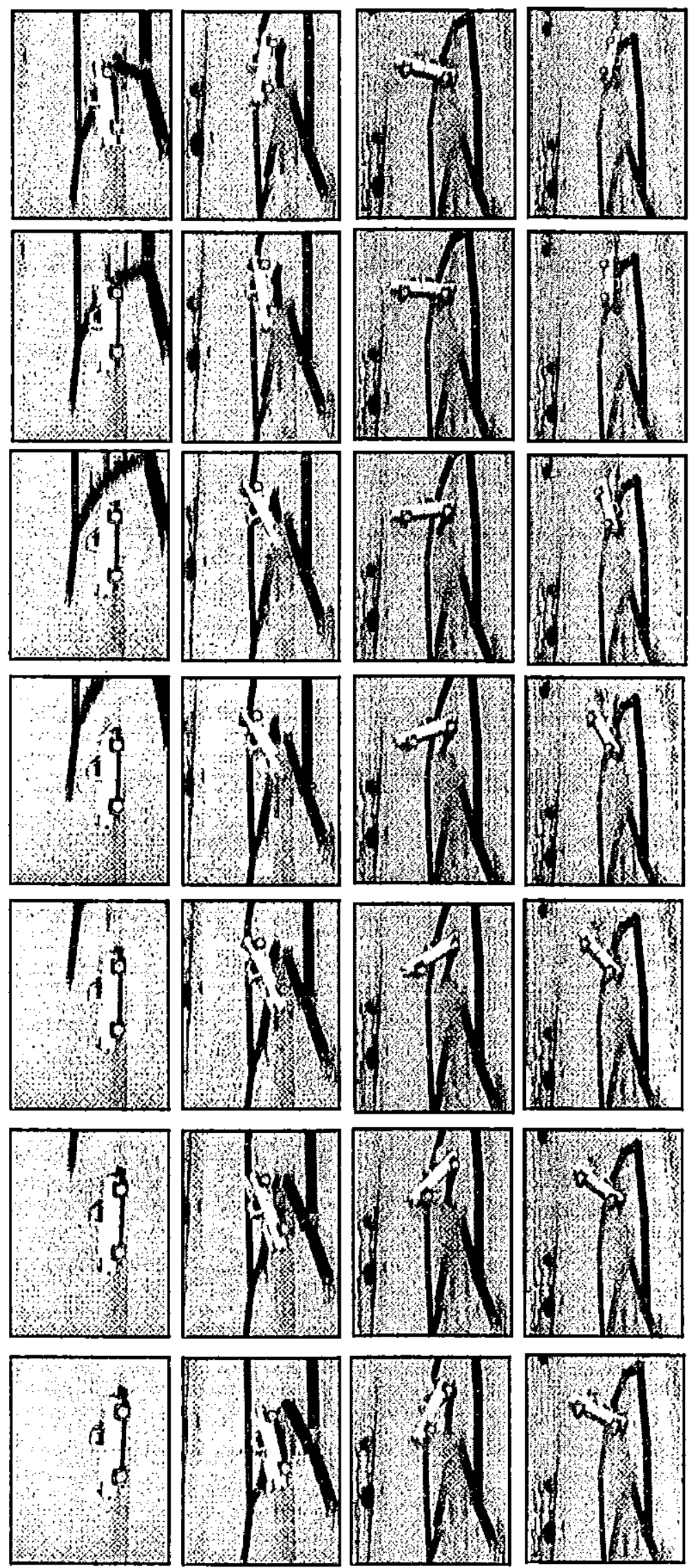

苟 